\title{
Correction to: Hissing like a snake: bird hisses are similar to snake hisses and prompt similar anxiety behavior in a mammalian model
}

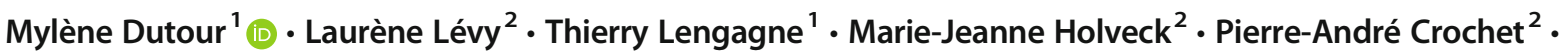 \\ Philippe Perret $^{2}$ - Claire Doutrelant ${ }^{2}$. Arnaud Grégoire ${ }^{2}$
}

Published online: 16 January 2020

(C) Springer-Verlag GmbH Germany, part of Springer Nature 2020

\section{Correction to: Behavioral Ecology and Sociobiology https://doi.org/10.1007/s00265-019-2778-5}

After publication of this paper, the authors determined an error in the article title.

It was captured as:

PC 1Hissing like a snake: bird hisses are similar to snake hisses and prompt similar anxiety behavior in a mammalian model.

It should be:

Hissing like a snake: bird hisses are similar to snake hisses and prompt similar anxiety behavior in a mammalian model.

Publisher's note Springer Nature remains neutral with regard to jurisdictional claims in published maps and institutional affiliations.

The online version of the original article can be found at https://doi.org/ $10.1007 / \mathrm{s} 00265-019-2778-5$

Mylène Dutour

mylene.dutour@hotmail.com

1 LEHNA, UMR5023, Université de Lyon, Université Lyon 1,

ENTPE, CNRS, 6 rue Raphaël Dubois, 69622 Villeurbanne, France

2 CEFE, UMR5175 CNRS, Université de Montpellier, Campus CNRS 1919 route de Mende, 34293 Montpellier Cedex 5, France 